The retention of condensation nuclei in the respiratory tract was dealt with by $F$. Verzár and P. J. Nolan. Based on experiments made by $T$. Burke and himself, Nolan stated that nuclei are not produced by breathing. Exhaled air contains 80-20 per cent of the nucleus content of the inhaled air. Mr. Claes Rooth summarized most ably the important work by C.-G. Rossby (Stockholm) and H. Egnér (Uppsala) on the synoptic variations in the chemical composition of atmospheric precipitation and made a strong plea for introducing measurements of carbon dioxide as a routine in meteorological networks.

In the geophysical laboratory of the School of Cosmic Physics, Dublin, equipment for determining concentration and size of condensation nuclei and for measuring their vertical gradient near the ground were demonstrated during the symposium. A small exhibition showed the development of the photoelectric nucleus counter. Among the exhibits were a photograph of the direct-beam photo-electric nucleus counter, and the original model of the multiflex photo-electric counter which L. W. Pollak designed and W. A. Morgan constructed in the offices of the Irish Meteorological Service at Foynes early in 1940. The proceedings of the symposium will be published as a separate volume of Geofisica Pura e Applicata (Milan). The next symposium on condensation nuclei is to take place in September 1956 in Switzerland.

L. W. Pollak

\section{TAPEWORMS OF THE FAMILY TETRABOTHRIIDAE}

$\mathrm{A}^{\mathrm{N}}$

$\mathrm{N}$ interesting and important paper by Prof. J. G. Baer has been published as a memoir of the University of Neuchâtel* on a taxonomic revision and biological study of the Cestodes of the family Tetrabothriidae parasitic in birds of the high seas and marine mammals. In the paper, Prof. Baer aims at classifying and simplifying the determination of this very difficult group of tapeworms, and seeks to show-with considerable success - that a parasite and its host are fundamentally inseparable. 'The two must be considered together.

The revision is based on the re-examination of more than seventy types of the eighty-odd species described, with the result that the number of species is reduced to forty, and only four of the eleven genera are retained. The monograph is divided into five sections, the first three of which are entirely given up to the descriptions of the species together with their synonyms, hosts and the more important bibliographical references. An introductory chapter deals with the general anatomy, and it is found that neither the size of the scolex nor the muscular development of the strobila are reliable taxonomic characters, as was formerly supposed to be the case. On the other hand, the structure of the genital atrium is stressed since it appears to yield by far the best and most reliable morphological character. This structure, however, can only be seen in transverse sections, and therefore no specific identification is possible if worms are mounted in toto. All the species

- Révision taxonomique et étude biologique des Cestodes de la famille des Tetrabothridae parasites d'oiseaux de haute mer et do nammiferes marins. By Jean G. Raer. Memoires de 1 Universite de are described in a uniform manner, and only the essential characters are stressed. The genital atrium of each species is illustrated, and all the drawings made to the same scale, so that comparisons are easily made, while a special section is devoted to the comparative anatomy of the species. It is found that the structure of the genital atrium reveals the existence of three distinct evolutionary trends, making it possible to split the species into distinct groups. A key for the identification of the species is thus established. The position of the family Tetrabothriidae is discussed and it is assigned to a now order, distinct from either the Pseudophyllidea or the Cyclophyllidea, but more closely related to the Tetraphyllidea.

Tetrabothriids are found to be extremely host. specific; each group of hosts-namely, Sphenisciformes, Procellariiformes, Pelecaniformes, Gaviiformes and Charadriiformos-harbours species distinct from those occurring in the others. Although the life-cycle of the tapeworms is unknown, it is postulated, on the basis of stomach contents of the sea-birds and mammals, that cephalopods might act as intermediate hosts. From statistical evidence it seems that the host can only become infested when leading a semi-sedentary life, that is, during the breeding season. This is also borne out by the fact that different hosts belonging to the same order nesting on the same island usually harbour the same species of tapeworm. Using the evolutionary trends of the genital atrium as a basis, combined with the results obtained from a statistical study of the distribution of the parasites among the hosts, it is found that there is distinct evidence of parallel evolution of both the tapeworms and their hosts. From these results it is postulated that the Sphenisciformes, Procellariiformes and Pelecaniformes might be derived from a common stock, and the Gaviiformes and the Alcae appeared later as side branches. The arguments and evidence put forward here by Prof. Baer are convincing, and one feels that his main conclusions are right. He also suggests that the species harboured by gulls have been acquired secondarily. But here he is not quite so confident; the case is certainly more open to argument, and one wonders if perhaps only one of the gull lines has been acquired thus.

I think, however, that Prof. Baer rather overemphasizes (p. 104) the apparent contradiction in the conclusions he reaches from the study of Tetrabothriids and the evidence deduced from a study of the Mallophaga. True, his conclusions are not entirely confirmed by the published work on the feather lice, but this is largely owing to the fact that evidence from the distribution of the Mallophaga is rarely helpful in the elucidation of the relationship between orders of birds. Thus the Mallophaga of the Sphenisciformes and Gaviiformes show no apparent relationship to those of other birds. While, although some of the Mallophaga of the Procellariformes, Pelecaniformes and Charadriiformes do not rule out a possible relationship between these orders, the evidence is in no way conclusive.

Finally, it must always be remembered that the classification of the birds themselves is in some cases still open to doubt, and the characters upon which families are assigned to certain orders may be less dependable than the characters chosen for classifying their parasites. Unfortunately, specialists are not often in a position to evaluate the classification of groups other than their own, and are chary of taking 
so much on trust. If Prof. Baer has discovered in the genital atrium a character which is dependablo-. a point which time alone will prove to everyone's satisfaction-it is a matter of great importance from the point of view of elucidating host/parasite relationships.

One minor point is worth noting: a fine trap is set for the English-speaking reader by the use here and there of vernacular names of the hosts. Thus, "Pingouin" equals razorbill, not penguin, and "Puffins" are shearwaters, not puffins in our sense. Miriam RothschiLD

\section{RADIO EMISSION FROM JUPITER}

$\mathrm{T}$ HE Carnegie Institution of Washington announced in April that radio emissions from Jupiter had been detected on a frequency of $22 \mathrm{Mc} / \mathrm{s}$. The receiving system consisted of a large cross aerial, of the type developed by Mills in Sydney for radio astronomy, which produces a narrow beam in a fixed direction. The Carnegie aerial occupies a 96-acre field near Seneca, Maryland, and although the beamwidth is not stated it may be deduced to be of the order of one degree from the fact that Jupiter passes through the aerial beam in six minutes. The radio emissions were reported to have the appearance of short random bursts of static resembling thunderstorm interference on a broadcast receiver and were observed about one day out of three during the time when Jupiter was in the beam of the aerial system. The location of the sky from which these bursts originated agreed with the position of Jupiter over a period of several months, and hence it can be presumed that any terrestrial origin of the bursts has thereby been excluded.

The study of radio waves from the sun is a wellknown and important part of radio astronomy. The signals are relatively intense; those from the quiet or undisturbed sun originate in the corona, which has an equivalent black-body temperature of the order of a million degrees at these low frequencies. Success has also been achieved in measuring the radio emission from the moon by Dicke and Beringer in 1946, and by Piddington and Minnett in 1949. In this case the emission measured, on a wave-length of $1.25 \mathrm{~cm}$., corresponds to the black-body radiation appropriate to a lunar surface temperature of $250^{\circ} \mathrm{K}$. 'The surface temperature of Jupiter measured at the top of the cloud layer is about $160^{\circ} \mathrm{K}$., and hence the signal bursts received by the Carnegie workers on $22 \mathrm{Mc} / \mathrm{s}$. must have quite a different origin from the solar or lunar emissions.

It has been suggested that the Jupiter signals are caused by disturbances in the planetary atmosphere similar to terrestrial thunderstorms, but on a much larger scale. It is possible to estimate the likelihood of this from the radiation field produced by a single lightning flash in the earth's atmosphere which, according to the measurements of E. T. Pierce, is $15 \mathrm{~V} . / \mathrm{m}$. at a distance of $20 \mathrm{~km}$. on a frequency of $1 \mathrm{Mc} / \mathrm{s}$. and band-width $1 \mathrm{Mc} . / \mathrm{s}$. At the distance of Jupiter the field-strength would be $5 \times 10^{-7} \mathrm{~V} . / \mathrm{m}$. and the power flux about $10^{-21}$ W. m..$^{-2}(\text { c. } / \mathrm{s} .)^{-1}$ at $1 \mathrm{Mc} . / \mathrm{s}$. Making reasonable assumptions about the frequency spectrum and remembering that in the terrestrial atmosphere the rate of occurrence is about a hundred flashes per second, it seems that the thunderstorm static from the earth at the distance of Jupiter would amount to about $5 \times 10^{-21}$ W. m.-2 (c./s.) ${ }^{-1}$, which would be readily detectable by contemporary techniques such as that used by the Carnegie workers. However, this signal would appear as a steady background, whereas the Jupiter signals occurred on only one day in three and were apparently in the form of bursts. It seems clear that the further development of this work may well provide new and valuable information about the conditions in the atmosphere of Jupiter.

\section{ABNORMAL PROTEIN ASSOCIATED WITH TOBACCO MOSAIC VIRUS \\ Structure of Polymerized Tobacco Plant Protein and Tobacco Mosaic Virus}

$\mathrm{W}$ HEN tobacco plants are infected with tobacco mosaic virus, an abnormal protein can be isolated from the tobacco leaves ${ }^{1}$. It has been demonstrated that this protein is non-infectious, is free of ribonucleic acid, and is immunologically related to the protein component of the virus. In addition, this protein has the peculiar property of polymerizing into rod-like structures when brought close to its isoelectric point at $p \mathrm{H} 3 \cdot 8$. In the electron microscope, these rods appear to be similar to tobacco mosaic virus rods, except that their length is more variable than that of freshly harvested tobacco mosaic virus.

There has been some debate concerning the exact nature of these nucleic acid-free rods, which appear so similar to tobacco mosaic virus, ${ }^{2,3}$. A recent amino-acid analysis has shown that the composition of the abnormal protein is virtually identical to that of the protein component of the virus ${ }^{4}$. Here we wish to present $\mathrm{X}$-ray diffraction evidence which demonstrates that the internal structure of the nucleic acid-free particles is similar to that of tho virus.

Samples of the abnormal protein from tobaceo plants were prepared by methods which have been described previously ${ }^{3}$. Freedom from contamination with tobacco mosaic virus was assured by the following tests : (a) When the abnormal protein is prepared in unpolymerized form at $p \mathrm{H} 7$, there is no highmolecular weight component observable in the ultracentrifuge, and no evidence of a rapidly migrating component in electrophoresis. (b) The ultra-violet absorption spectrum is that of a protein free of nucleic acid, with the ratio of optical densities at $280 \mathrm{~m} \mu$ and $260 \mathrm{~m} \mu$ of $1 \cdot 6-1 \cdot 7$; for tobacco mosaic virus this ratio is $0 \cdot 83$. (c) Electron micrographs of unpolymerized abnormal protein show no tobacco mosaic virus-like rods. (d) The material is not infectious. In summary, the contamination of abnormal protein by tobacco mosaic virus, if any, should be considerably less than 1 per cent.

The abnormal protein was gradually brought to its isoelectric point, and typical rod-like forms were observed in the electron microscope. Oriented airdried films of this material and of tobacco mosaic virus grown on the same tobacco plants were prepared by the microscope slide technique of Bernal 